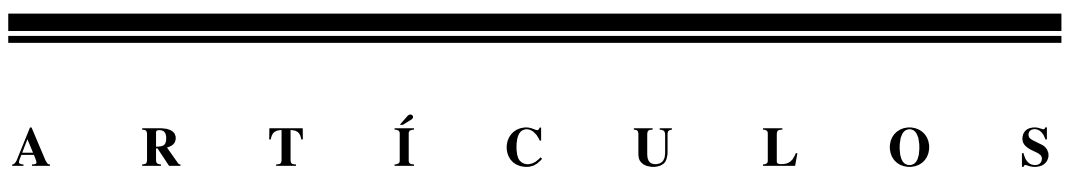




\title{
¿QUÉ DERECHOS TENEMOS?
}

\author{
Liborio L. Hierro \\ Universidad Autónoma de Madrid
}

\section{Introducción ${ }^{1}$}

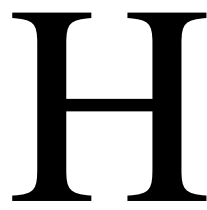

ace poco más de doscientos años, cuando los derechos humanos eran una idea balbuciente, el señor Thomas Paine alzó su voz contra la muy autorizada de su antiguo amigo el señor Burke -el cual se había referido a los «despreciables papeles emborronados que hablan confusamente de los derechos del hombre»- y se atrevió a responderle: « ¿Es que con esta frase quiere el señor Burke negar que el hombre tenga algunos derechos? Si éste es su propósito, tiene que decir que que no existen tales cosas como derechos en ningún lugar y que él mismo no posee ninguno» (Paine [1791-2] 1986, p. 58). Paine tenía razón, por lo menos, en el aspecto de que si nos importan nuestros derechos, simplemente si nos atrevemos a invocarlos, entonces quiere decir que afirmamos que existen derechos y, entonces, no preocuparse de los derechos ajenos podría ser una inconsecuencia de graves consecuencias. En el siglo que acaba ahora así ha ocurrido, según se expresó en el Preámbulo de la Declaración Universal de Derechos Humanos, ${ }^{2}$ y lo pe-

${ }^{1}$ Este trabajo forma parte del Proyecto de Investigación PB97-1434 financiado por la Dirección General de Enseñanza Superior e Investigación Científica. Originalmente, en una versión más breve, fue el texto de una conferencia pronunciada el 16 de Marzo de 1999 en la Facultad de Derecho de la Universidad Ramon Llull de Barcelona, en el Seminario Permanente de Derechos Humanos que anualmente organiza el Dr. Antonio Marzal; allí fue comentada por el Prof. García Manrique. Será publicado como parte de un libro colectivo que la Facultad de Derecho de ESADE edita periódicamente con los materiales del Seminario bajo la responsabilidad, como editor, de Antonio Marzal con cuyo consentimiento lo publico aquí. La casualidad hizo que también pronunciase aquella conferencia el día anterior en la Facultad de Derecho de la Universidad Autónoma de Madrid, en las jornadas conmemorativas del 50 Aniversario de la Declaración Universal de Derechos Humanos organizadas por la asociación de estudiantes CEINP. Posteriormente fue objeto de discusión en una sesión del Seminario del Área de Filosofía del Derecho de la U.A.M. Agradezco a Ricardo García Manrique y a todos mis compañeros del Área sus comentarios críticos que han servido para corregir, al menos en parte, sus deficiencias.

2 Su segundo párrafo, como es generalmente conocido, afirma: «Considerando que el desconocimiento y el menosprecio de los derechos humanos han originado actos de barbarie ultrajantes para la conciencia de la humanidad...». 
or, como dijo el mismo Paine, es que «lo que ha acontecido puede acontecer de пиеvo» (ibidem, p. 215).

A pesar del medio siglo transcurrido desde que se proclamó la Declaración Universal de Derechos Humanos dudo que tengamos todavía la perspectiva necesaria para ser conscientes de lo que ha supuesto. Lo que pretendo hacer a continuación bien podría considerarse una glosa de la Declaración aunque apenas hablaré de ella. Como tantas veces se ha puesto de relieve, el desarrollo de la «retórica de los derechos» ha corrido mucho más deprisa que el de la elaboración teórica y todavía hoy lo sigue haciendo con tal ritmo que parece conducirnos a una imparable inflación de derechos al precio de dejarnos atrapados en las redes de la trivialidad. ${ }^{3}$ Por ello lo único que pretendo ahora es dar cuenta de lo que a mi entender sería el estado actual de una Teoría moral de los Derechos Humanos.

Cuando -en la invitación que originalmente dio lugar a este trabajo- se me sugirió desarrollar la idea de un «núcleo duro» de los Derechos Humanos tal sugerencia me suscitó dos posibles interpretaciones. En una primera interpretación la cuestión parecería ser una cuestión de limpieza semántica: esto es, ¿cómo definir lo que entendemos por «derechos humanos», a los que parece corresponder una exigibilidad moral particularmente fuerte, evitando la inflación semántica que obviamente padecemos? Pues, en efecto, la idea de que los «derechos humanos» tienen una especial importancia moral ha generado un especial «pedigrí» de tal modo que cualquiera que pretende hoy el respeto de cualquiera de sus deseos, la protección de cualquiera de sus intereses o la satisfacción de cualquiera de sus necesidades prefiere formularlos como «derechos» que asumir la costosa carga de demostrar por qué sus deseos han de ser respetados, sus intereses protegidos o sus necesidades satisfechas. Parece como si al calificar ese deseo, ese interés o esa necesidad como un «derecho» uno quedase automáticamente exento de tener que demostrar su exigibilidad. Se produce una especie de ecuación semántica: es mi «derecho», luego debe ser respetado o satisfecho. Este sencillo atajo semántico es el que nos ha conducido a esa inflación de los «derechos humanos» entre los que hoy parecen incluirse junto a aquellos modestos derechos «naturales» del hombre -como el derecho a la vida, a la libertad y a la búsqueda de la felicidad- que Jefferson consideraba evidentes por sí mismos y que sólo exigían que el Estado se abstuviese de actuar contra ellos, los más exigentes derechos llamados sociales o de «segunda generación» como el derecho al trabajo, a la educación o a la vivienda, que exigen que el Estado actúe en su satisfacción, y los nuevos derechos de «tercera» e incluso «cuarta» generación entre los que florecen todo tipo de pretensiones y todo tipo de pretendientes. Se habla, hoy, de derechos humanos en virtud de condiciones o situaciones especiales, como de los derechos de la mujer en atención al gé-

${ }^{3}$ Vid. F. Laporta 1987, p. 23 y p. 44; L. W. Sumner 1990, p. 1 («Like the arms race the escalation of rights rhetoric is out of control») y p. 15.; M. Walzer 1993, p.13. 
nero, de los derechos del niño o de los derechos de los ancianos en atención a la edad, o de los derechos de los discapacitados en atención a sus condiciones físicas, y se habla también de los derechos de colectivos humanos como pueblos, razas o etnias, así como de los derechos de los no nacidos, de las generaciones futuras, de los animales e incluso de los derechos de la naturaleza ${ }^{4}$; se habla, por otra parte, de cosas tales como el derecho a la paz, el derecho a la autodeterminación informativa, el derecho a la calidad de vida, el derecho al medio ambiente, etc. etc.; porque, como decía, parece que cualquier cosa o situación que necesitemos, nos interese o simplemente nos apetezca queda más perentoriamente reclamada si decimos que es «nuestro derecho». Así que mi primera interpretación de la cuestión sería la siguiente: ¿es posible delimitar un catálogo estricto de los derechos humanos? ¿es posible establecer claramente en qué consiste el «pedigrí» de los derechos humanos y, en consecuencia, conceder tan noble denominación a determinados deseos, intereses o necesidades y negársela a otros?

Pero hay -me parece- una segunda posible interpretación de aquella sugerencia. Consistiría en saber si, dado un catálogo de los «derechos humanos», hay entre ellos algunos que tienen una especial jerarquía o una especial resistencia de modo que, en caso de conflicto, unos (los más fuertes) prevalecerían sobre los otros (los más débiles). De ser esto así, podríamos decir que los primeros, los derechos más fuertes, más resistentes o - por decirlo más claramente- «más valiosos» constituirían el núcleo duro de los derechos humanos y los otros, los más débiles, menos resistentes o «menos valiosos», constituirían su periferia.

Ambas posibles interpretaciones de la invitación suscitan sendas cuestiones que, en principio, son independientes entre sí porque, por un lado, sea cual fuere el número de los «derechos humanos» podría haber dentro de ellos dos o más categorías de importancia y, por otro lado, si alguna razón nos impidiese distinguir dentro de ellos categorías diferentes esta conclusión ni aumentaría ni reduciría por sí sola el número de candidatos al «pedigrí» de «derechos humanos». Consecuentemente parece que ambas cuestiones han de tratarse con independencia. Podría ocurrir, sin embargo, que de la respuesta a la primera pregunta se derivase la respuesta a la segunda, es decir que una cierta reconstrucción teórica de lo que entendemos por «derechos humanos» y de la fundamentación de su peculiar importancia moral y política arrastrase necesariamente una determinada ordenación jerárquica de los derechos.

${ }^{4}$ La presentación está obviamente simplificada. Sin duda cuando hablamos de derechos de la mujer la distinción por género es relevante en tanto en cuanto la mujer viene padeciendo una amplia discriminación precisamente por razón de género; en el caso de niños o mayores la distinción por edad es relevante bien por previa discriminación o bien por diferencia de condiciones físicas, o por ambas. Un cuadro general, especialmente por lo que se refiere a animales y naturaleza, puede verse en Silvana Castignone, Nuovi Diritti e Nuovi Soggetti, Edizioni Culturali Internazionali Genova, Genova, 1996. 
Me gustaría rechazar desde un principio una razón puramente intuitiva que parece abonar la idea de que los «derechos humanos» deben ser muy pocos. Es la intuición «económica» de acuerdo con la cual el valor de algo tiene una estrecha dependencia con su escasez. Como es sabido la ciencia económica nació vinculada a la observación empírica de que el precio de los bienes depende más de su escasez que de su aptitud para satisfacer necesidades básicas y eso fue lo que obligó a distinguir entre el valor de uso y el valor de cambio, distinción que Adam Smith resumió en la paradoja del agua y los diamantes (Smith [1776] 1987, p. 30). Esta constatación se ha extendido de tal modo en nuestros paradigmas culturales que es general la idea de que si algo vale mucho ha de ser escaso o que si algo es abundante entonces vale poco. Pero esta intuición incide en la falacia de confundir valor y precio. Las cosas nos valen, no sólo en sentido moral pero también en sentido moral, por su importancia para satisfacer nuestras necesidades, como nos vale el agua que bebemos o el oxígeno que respiramos, sea cual fuere su abundancia y, por ella, su precio. Pienso, por tanto, que no debemos acercarnos a la primera cuestión -esto es: ¿cuántos son los derechos humanos?- con un prejuicio elitista que diría algo así como «si son pocos, son mejores». ${ }^{5}$ Lo que sí debemos hacer es acercarnos a la cuestión con una preocupación antiinflacionista, es decir huyendo rigurosamente de la tentación contrapuesta que diría algo así como «si son buenos, que sean muchos».

Por lo tanto quiero plantear esta primera cuestión sin ningún prejuicio cuantitativo. Lo que me parece interesante es intentar delimitar rigurosamente qué entendemos por «derechos humanos», intentar justificar rigurosamente cuál es el fundamento moral de tales «derechos humanos»y, entonces y sólo entonces, concluir cuáles son los candidatos aptos para tan noble título. La cuestión así planteada implica, sin embargo, tal cantidad de problemas de concepto, fundamentación y consecuencias normativas que difícilmente se podrían abordar en el limitado espacio de este trabajo. Necesariamente habrá que dar algunas cuestiones por sabidas y otras por discutidas para poder presentar unas hipotéticas conclusiones.

\section{2. ¿Qué son los «derechos humanos»?}

Se ha puesto de relieve por muchos autores que cuando utilizamos conceptos normativos resulta casi imposible separar la delimitación conceptual

\footnotetext{
${ }^{5}$ Laporta ha defendido la tesis de que los derechos humanos han de ser pocos si se les ha de atribuir una especial fuerza moral. Pérez Luño le ha opuesto un argumento empírico conforme al cual la experiencia práctica demuestra que la mayor extensión de los derechos va acompañada de una mayor intensidad en su protección. Laporta ha replicado sugiriendo una relación entre la opulencia en el disfrute de los derechos por unos y la correlativa miseria de otros: aun cuando aquella opulencia no sea la «causa directa» de ésta miseria, señala Laporta, sí que implica considerables recursos económicos y el riesgo de un desprestigio de los derechos humanos si «para tener dignidad moral hay que tener fortuna geopolítica de nacimiento» (Laporta 1987, p. 23; 1987 (2), pp. 74 y 77; Pérez Luño 1987, p. 61).
} 
del problema de la fundamentación, es decir separar el nivel de la descripción del nivel de la justificación (Laporta 1987, p. 23). Creo, sin embargo, que la cuestión conceptual es, al menos analíticamente, previa. Los derechos humanos parecen ser un tipo o especie del género de los «derechos subjetivos». La noción misma de «derecho subjetivo» es relativamente moderna y aparece ligada a la afirmación del individuo como soberano sobre sí mismo, afirmación que se desarrolla paralelamente a la del Estado como soberano colectivo. ${ }^{6}$ El derecho subjetivo en su origen es el ámbito de soberanía que cada uno tiene sobre sí mismo y sobre sus bienes, o sea un derecho de propiedad. Parece que fue en el siglo XIV, en las obras de Guillermo de Occam y de Jean Gerson, cuando se equipararon por vez primera el «dominium» y el «ius» aunque el acta de nacimiento del concepto moderno de derecho subjetivo es unánimemente atribuido a un pasaje de Hugo Grocio que consagraba esta misma identidad. ${ }^{7}$ Desde entonces quedó fuertemente arraigada en nuestra cultura jurídica la idea de que un derecho subjetivo es un poder de la voluntad y esta es la idea que subyace en las declaraciones de derechos del período de las revoluciones. La cultura jurídica del positivismo asumió y desarrolló esta tesis y hubo de pasar más de un siglo para que se pusiera en cuestión. Fue a partir de la crítica de Ihering al voluntarismo y del aparato analítico ofrecido por Hohfeld cuando pudimos empezar a concebir los derechos subjetivos de forma más amplia y más

${ }^{6}$ No parece ocioso recordar, a estos efectos, que para el mismo Bodino «la verdadera felicidad de una república y la de un individuo son una y misma cosa» que se reduce a alcanzar las virtudes intelectivas y contemplativas (Bodino [1576] 1973, p. 14).

${ }^{7}$ Además de la reconstrucción histórica, ya clásica, de Richard Tuck (Tuck 1979, pp. 2627 y 58 y ss.) puede verse H. Matsuo 1995, p. 12: «Thus the definition of dominium as power or faculty infiltrated into that of ius, and at the same time such a concept of ius as one's own faculty came to be distinct from law (lex) and assimilated with liberty (libertas).» Ha sido Michel Villey quien ha afirmado con mayor contundencia que la «cuna» del derecho subjetivo fue la orden franciscana (Villey 1964, p. 98: «le berceau du droit subjectif fut l’ordre franciscain») y quien ha considerado que Occam fue el «padre» de la noción de derecho subjetivo (ibidem, p. 98) por su análisis conceptual de las diversas formas de potestad (derivadas del «ius poli» o del «ius fori») y de su carácter facultativo, lo que constituyó el núcleo teórico de su enfrentamiento con Juan XXII en el debate sobre la pobreza franciscana. En efecto, la afirmación del carácter facultativo y por ello renunciable de las potestades constituiría el núcleo del Opus nonaginta dierum de Occam, contestación a la bula pontificia Quia vir reprobus que Juan XXII había dirigido contra el general de la orden franciscana Miguel de Cesena.

El pasaje clásico de Grocio es aquél en que, tras establecer un primer significado de «derecho» como aquello que es justo, afirma: «Ab hac juris significatione diversa est altera, sed ab hac ipsa veniens, quae ad personam refertur: quo sensu jus est, Qualitas moralis personae competens ad aliquid juste habendum vel agendum... Facultatem Jurisconsulti nomine sui appellant, nos posthac ius proprie aut stricte dictum appellabimus; sub quo continentur potestas, tum in se, quae libertas dicitur, tum in alios; ut patria, dominica: Dominium, plenum sive minus pleno, ut ususfructus, jus pignoris: \& creditum, cui ex adverso respondet debitum.» (Grocio [1625] 1987, p. 54). Debe notarse que aparecen en Grocio claramente enunciadas algunas de las modalidades de derecho subjetivo que hoy desarrollamos siguiendo a Hohfeld: las de libertad, potestad (o competencia) y pretensión (o crédito). 
acorde con el uso habitual que se había ido desarrollando en el lenguaje jurídico. Hoy sabemos que lo que denominamos «derechos subjetivos» son posiciones normativas, esto es posiciones o situaciones de un sujeto cuya conducta está regulada por normas, y que denominamos «derechos» a aquellas posiciones normativamente establecidas en que un sujeto tiene una libertad protegida para actuar, una pretensión protegida para beneficiarse de una conducta ajena, una potestad establecida para ordenar la conducta de otros, o una inmunidad protegida frente a la potestad de otros. Y la idea de que son «derechos» implica la convicción, siquiera sea desde el punto de vista interno a las normas, de que son situaciones que favorecen la capacidad de acción del sujeto. Enfrente de ellas se encuentran los deberes que son, en términos de Hohfeld, correlativos: la obligación de abstenerse de interferir la libertad ajena, la obligación de satisfacer la pretensión de otro, la sujeción a una potestad o la incompetencia para ordenar la conducta del otro. Estas son las situaciones a las que denominamos «deberes» y que implícitamente consideramos situaciones negativas porque limitan la capacidad de acción del sujeto. ${ }^{8}$

Afirmar que los «derechos humanos» son una especie del género de los derechos subjetivos, es decir un conjunto de libertades, pretensiones, inmunidades y potestades no es un simple alarde teórico. Es, en realidad, una afirmación necesaria para ganar la primera batalla en la lucha por los derechos humanos en el frente de la Teoría. Porque la Ciencia Jurídica ha servido como parapeto unas veces y como obstáculo otras contra su desarrollo jurídico positivo con el fácil expediente de negar que los «derechos humanos» fuesen «derechos» en sentido propio. Incluso entre autores nada sospechosos de desafección a los derechos humanos el problema teórico les ha obligado a conceder que los «derechos humanos» eran sólo principios, o criterios, o pretensiones ideales, o buenos propósitos pero en ningún caso «derechos subjetivos» hasta que un Ordenamiento Jurídico los declaraba e instrumentaba de forma positiva. ${ }^{9}$

De este modo podemos establecer una primera conclusión. Los derechos humanos son derechos subjetivos aun cuando sean derechos subjetivos morales lo que sólo significa que del mismo modo que un derecho subjetivo jurídico-positivo es una posición normativa que se deriva de una norma jurí-

${ }^{8}$ El tratamiento conceptual de los derechos y deberes como posiciones o situaciones normativas procede, como es sabido, de W. N. Hohfeld, Some fundamental legal conceptions as applied to judicial reasoning, Yale Law Journal, 23, 1913; tuvo un desarrollo particularmente relevante en A. Ross, On Law and Justice, Stevens \& Sons, Londres, 1958 (Capítulo V) y Directives and Norms, Routledge \& Kegan Paul, Londres, 1968 (Capítulo V, \& 27, 28 y 29); la literatura posterior es extensísima (vid., en la literatura española, L.L. Hierro 1982, M. Atienza 1986-7, J.R. Páramo 1986-7 y J.R. Páramo 1996).

9 Vid. por todos, Ross 1971, p. 129 y Hart 1982, p. 192. Entre nosotros, la vinculación conceptual del «derecho subjetivo» con el «Derecho objetivo» ha llevado a G. Peces-Barba a sostener una teoría dualista (Peces-Barba 1980, pp. 24-27; 1991, pp. $95-97$ [donde considera que el nivel moral y el jurídico han de completarse con el de la eficacia] y 1995, p. 187). 
dica, un derecho subjetivo moral es una posición normativa que se deriva de una norma o de una razón moral. ${ }^{10}$ Es claro, sin embargo, que ni todos los derechos subjetivos jurídicos (que puedan encontrarse en la tierra del Derecho Positivo) ni todos los derechos subjetivos morales (que puedan ser soñados por los teóricos o los filósofos del Derecho) son candidatos iguales a la denominación de «derechos humanos», por lo cual la segunda parte del desafío conceptual consiste en establecer cuál es la característica específica que convierte a algunos «derechos» (a algunas libertades, pretensiones, inmunidades y potestades) en «derechos humanos», es decir en derechos a favor de cuya protección legal hay particulares razones morales. Porque parece que es ésta la característica moralmente definitoria de lo que se denomina «derechos humanos»: la exigencia moral de que sean jurídicamente protegidos. Sin duda yo puedo sostener que cualquiera tiene una pretensión moralmente legítima a que sus amigos le sean fieles (es decir, tiene el derecho moral a la fidelidad) pero yo no sostendría, ni conozco a nadie que lo haga, que tal derecho moral debe ser especialmente protegido por el sistema jurídico. ¿Qué derechos son, entonces, los que ostentan esa peculiar característica?

Aquí la tarea se complica porque uno puede limitarse a constatar qué es lo que otros, sea que se trate de cualificados autores o de la mayor parte de la gente en un contexto dado, han utilizado o utilizan como razones relevantes, o bien puede aspirar a proponer por su cuenta una o varias. Si opta por esta segunda posibilidad abandona el cómodo terreno de la descripción de valores y normas y se compromete a tomar parte en el incómodo juego de valorar y prescribir. Pero esta es la única forma de decir cosas interesantes y, naturalmente, implica la introducción en el campo de la definición de compromisos valorativos. Creo que para delimitar lo que deberíamos entender por «derechos humanos» son necesarias dos restricciones. En primer lugar lo que debemos entender por «derechos humanos» no son todos los deseos, intereses o necesidades relevantes de un agente humano sino sólo aquellos deseos, intereses o necesidades que pueden instrumentarse normativamente como derechos subjetivos, esto es como libertades, pretensiones, inmunidades o potestades lo que excluye, por ejemplo, cualquier pretensión imposible de satisfacer (Hierro 1982, pp. 54 y 59); en segundo lugar, tampoco son todas las posiciones que jurídicamente pueden instrumentarse co-

${ }^{10}$ Vid. J. L. Mackie 1984, passim; J. Feinberg 1980, p. 154; L. W. Sumner 1990, pp. 132151; C. Wellman 1995, p. 48; en España: F. J. Laporta 1987, pp. 33-35; y A. Ruiz Miguel 1990, passim.

E. Fernández (1984, pp. 104-110) utiliza los términos «derechos morales» pero con una referencia idéntica a la teoría dualista de Peces-Barba; A. E. Pérez Luño (1984, pp. 177-180) señala la falta de claridad del calificativo «morales» y defiende su equiparación a «derechos naturales»; N. Bobbio (1991, pp. 19-20) ha expresado sus dudas frente a la recepción de la locución anglosajona «derechos morales» y R.J. Vernengo (1989, passim) ha desarrollado una crítica completa y radical de la expresión «moral rights» («un hueso duro de tragar»). 
mo derechos subjetivos sino sólo aquellas que tienen una cierta característica moral, a saber: que son condición necesaria para que una persona, un ser humano, pueda desenvolverse como agente moral en un contexto dado.

Que son condición necesaria significa que la definición incluye todas y cada una de aquellas situaciones o posiciones normativas positivas cuya negación o desconocimiento normativo implicarían una limitación sustantiva del sujeto paciente para desenvolverse como agente moral en ese contexto. Significa también, por otra parte, que la definición excluye cualquier posición o situación normativa cuyo reconocimiento o satisfacción no es necesaria para que el sujeto se desenvuelva como agente moral en ese contexto. Por ilustrarlo con sólo dos ejemplos. La inclusión supone, por ejemplo, que en un contexto social con un alto grado de comunicación escrita, la pretensión de recibir una alfabetización que permita operar en condiciones básicas de competencia comunicativa se convierte en un derecho humano; la exclusión supone, por ejemplo, que en un contexto social en que el conocimiento del idioma ruso no es un requerimiento básico para la competencia comunicativa la pretensión de recibir una enseñanza del idioma ruso no es un derecho humano.

Un segundo elemento caracterizador de lo que se viene entendiendo por «derechos humanos» es su carácter fundamental lo que suele entenderse como que sirven de fundamento legitimador de los sistemas jurídicos. ${ }^{11}$ Es una vieja idea acuñada por el iusnaturalismo racionalista que supo resumir lapidariamente el señor Jefferson en el Preámbulo de la «Declaración de Independencia»: «que para garantizar estos derechos se instituyen entre los hombres los gobiernos, que derivan sus poderes legítimos del consentimiento de los gobernados». Puesto que no pretendo ofrecer una definición nominal o meramente explicativa, sino una definición estipulativa de carácter valorativo he de señalar que, en ella, este segundo carácter que podríamos denominar el «carácter legitimador» tiene una función subordinada a la del carácter anterior. Es decir, sólo asumiendo que el primer valor moral se sitúa en la autonomía del individuo (Mackie 1984, p. 176; Alexy 1995, p. 26) sólo entonces los derechos humanos tienen carácter fundamental (o legitimador) y ofrecen una respuesta completa a los tres grandes problemas teóricos de la Justicia: por qué es justo ordenar (la Justicia como legalidad), quién está justificado para ordenar (la Justicia como legitimidad en origen) y qué es lo que está justificado ordenar (la Justicia como legitimidad en contenido). Los derechos humanos ofrecen una respuesta completa porque en base a un mismo principio resuelven las tres cuestiones: las normas son le-

${ }^{11}$ Aunque es frecuente hoy reservar el apelativo «fundamentales» para aludir a los derechos humanos positivizados, con un rango especial, en un orden jurídico (Pérez Luño 1984, p. 31) históricamente parece anterior la idea de que eran fundamento del orden jurídico-político (ibidem, p. 30) y derivada de ella la idea, posterior, de que requerían un puesto especial en el sistema jurídico «generalmente en el nivel superior de la jerarquía normativa» (Peces Barba 1980, p. 14, donde también se refiere a su carácter legitimador). 
gítimas porque son necesarias para el desarrollo de la autonomía individual, la competencia normativa es legítima si y sólo si deriva del ejercicio de la autonomía por los destinatarios de las normas (esto es, del consentimiento) y las normas son justas si y sólo si tienen como contenido la protección y la promoción de esa misma autonomía. Este fuerte carácter «fundamental» de los derechos humanos remite inevitablemente al problema de su fundamento moral, lo que significa algo así como desvelar el fundamento del fundamento. Antes de aventurarme en este terreno me atrevería a resumir esta primera discusión conceptual ofreciendo una definición, que es al fin y al cabo lo que pretendía encontrar.

(1) Los derechos humanos son aquellas libertades, inmunidades, pretensiones y potestades que corresponden a todo ser humano como condición necesaria para realizarse como sujeto moral y cuya satisfacción es condición necesaria y suficiente para justificar la existencia, el origen y el contenido de un sistema jurídico. ${ }^{12}$

\section{El fundamento moral de los derechos humanos}

Resulta arriesgado discrepar de uno de los mejores filósofos del Derecho de este siglo como lo es Norberto Bobbio, siendo además uno de los maestros de mi generación, pero creo que se equivocó doblemente en esta cuestión. Tanto por negar que el problema de la fundamentación fuese relevante como por negar que pudiese encontrarse un fundamento único (Bobbio 1991, Capítulo III). No me parece necesario extenderme en explicar la primera discrepancia: fundamentar nuestros juicios de valor es una consecuencia de nuestra racionalidad reflexiva y fundamentar juicios de valor de carácter moral es además un requisito necesario de su pretensión de universalidad. Parece conveniente recurrir a una distinción sencilla y muy generalmente aceptada para dividir, previamente y bajo el punto de vista metaético, las diferentes fundamentaciones morales de los derechos humanos en dos grandes grupos: de un lado las de carácter cognoscitivista, que incluirían fundamentaciones iusnaturalistas en sentido estricto, fundamentaciones historicistas o fundamentaciones intuicionistas (como la que parecían albergar los redactores de la Declaración de Independencia), y de otro lado las

${ }^{12}$ Esta tesis desarrolla lo que sostuve en Hierro 1982 y creo que coincide sustancialmente con las dos conclusiones de Gewirth 1990 (el original es de 1981), p. 145. «Lo que hemos tratado de mostrar en este ensayo -dice- es que todos los derechos humanos tienen un fundamento racional en las condiciones necesarias o necesidades de la acción humana, de modo que ningún agente humano puede denegarlas o violarlas so pena de autocontradicción. Así, las demandas que los derechos humanos hacen a las personas se justifican por el PCG (Principio de Consistencia Genérica) en cuanto principio supremo de la moralidad. Es también a través de las exigencias morales establecidas por este principio como el orden político y jurídico recibe su justificación central en cuanto provisor de la protección de los derechos humanos» (resaltados míos). No cabe afirmar que los derechos humanos son, además de condición necesaria, condición «suficiente» para realizarse como sujeto moral-como me hizo ver R. García Manrique- porque han de darse otras condiciones extranormativas como, por ejemplo, ciertos niveles mínimos de salud física y mental. 
de carácter no cognoscitivista. Pues bien, cuando uno se aleja de la pretensión reiteradamente falsada de que los juicios de valor expresan conocimiento se aleja también necesariamente de la pretensión de formular una Teoría de la Justicia de carácter sustantivo o teleológica en la que los derechos humanos podrían entenderse como estados de cosas o situaciones buenas y a las que, por ello, las normas jurídicas deberían encaminarse. Alternativamente, la cuestión procedimental parece convertirse entonces en la cuestión central, es decir en la única posibilidad de reconstruir una fundamentación racional de lo que es bueno o justo porque se deriva de un procedimiento racionalmente correcto de evaluación y decisión. En esta alternativa se situarían las fundamentaciones contractualistas y constructivistas de raíz kantiana. ${ }^{13}$ En otro lugar he tratado de demostrar, sin embargo, que todas estas teorías que podríamos denominar «procesales» de la Justicia y que en su mayoría abocan a una fundamentación consensual de los derechos humanos tienen necesariamente en común, aunque no siempre de forma explícita, una determinada concepción normativa de la persona como agente moral (Hierro 1998). En el caso de Rawls lo que inicialmente no estaba explícito terminó por hacerse conscientemente explícito y él mismo declaró que toda su teoría se apoyaba en esa concepción normativa de la persona. Lo mismo sucede, de forma explícita desde un principio, en la teoría de los derechos de Ronald Dworkin o cuando Robert Alexy propone una fundamentación de los derechos humanos en la ética discursiva para concluir que tal construcción teórica se apoya en una concepción de la autonomía de la persona. ${ }^{14}$

La concepción moral de la persona como agente autónomo es cabalmente el prerrequisito de toda argumentación moral, como Kant dejó establecido, y es el fundamento necesario, suficiente y unitario de los derechos humanos cuando éstos son entendidos precisamente como las situaciones normativas que constituyen condición necesaria para que la persona se desenvuelva como agente moral en su contexto. La difusa pero poderosa idea de la dignidad humana (Dworkin 1984, p. 295) estriba precisamente en esa afirmación de la autonomía personal sin la cual cualquier discurso moral simplemente carece de sentido.

\section{4. ¿Qué derechos tenemos?}

Existe una larga tradición que reduce los derechos humanos básicamente a tres valores, principios o criterios: la libertad, la igualdad y la seguridad (Fernández 1984, p. 120). No discutiré ahora las pretensiones de algunos

${ }^{13}$ Sobre las diversas fundamentaciones es imprescindible el libro de L. W. Sumner, The Moral Foundations of Rights, Clarendon Press, Oxford, 1990.

${ }_{14}$ Vid. particularmente Rawls 1989, Dworkin 1984 y Alexy 1995. Gewirth (1990, pp. 129130 y 145) sostiene que hay una inferencia lógica necesaria entre las condiciones necesarias de la acción humana y su exigencia como derechos por cualquier agente. 
nuevos candidatos, como la solidaridad, sino que me limitaré a tratar de reformular estos tres valores o principios como derechos subjetivos básicos en sentido propio y a desvelar su contenido en cuanto candidatos a una nómina completa de derechos humanos.

\subsection{El derecho a la libertad}

Tres cuestiones continúan básicamente siendo disputadas en torno a la libertad como derecho humano. Si existe o no un derecho general a la libertad, cuáles son y cómo se relacionan las formas de la libertad y el carácter cualitativo de la libertad.

Sabemos que no es concebible un derecho a una libertad general si por esto se entiende a una libertad de acción sin límites, una especie de permiso irrestricto para actuar como uno quiera. El primer límite de una libertad relacional ${ }^{15}$, es decir normativamente protegida en relación con los demás, es el de la igual libertad ajena. La libertad natural -si es que tal cosa existe- sólo es normativamente concebible en los términos en que Kant formuló el imperativo categórico para el Orden Jurídico (Kant [1797] 1978, pp. 80-81). Sin embargo ello no significa que, contra cierta conclusión precipitada a que podría llevarnos la opinión de Dworkin (Dworkin 1984, pp. 380 y ss. $)^{16}$, no pueda afirmarse un derecho moral general de libertad esto es un permiso general para hacer todo aquello que las normas «legítimamente» no nos prohiben hacer u obligan a hacer de modo expreso. Si la autonomía personal es, como es, un prerrequisito del discurso moral y si la libertad del agente es, como es, un prerrequisito del significado prescriptivo de las normas, entonces a cualquier agente moral ha de reconocérsele y protegérsele su libertad para hacer o no hacer aquello que no está prohibido o es obligatorio so pena de cancelar su condición de agente moral. La idea de un «permiso débil» de carácter general (en el sentido de Von Wright [Von Wright 1979, p. 101]) o la idea de una «norma general excluyente» (en el sentido de Zittelmann) se convierten así en un derecho moral básico. Naturalmente que es concebible un orden normativo que estableciese una norma general excluyente de carácter prohibitivo ${ }^{17}$ y todavía más frecuente es, en el terre-

${ }^{15}$ Doy por supuesto el carácter relacional de los derechos en cuanto posiciones normativas. Vid. Hierro 1982 y Alexy 1993, p. 201.

${ }^{16}$ Como es sabido, la negación de un derecho general a la libertad es el eje de la argumentación de Dworkin (1984, Capítulo 12) para sostener la prioridad del derecho a la igualdad. Vid. la discusión de la tesis de Dworkin en J. L. Mackie 1984, pp. 177-178.

${ }^{17}$ Durante años busqué sin éxito algún ejemplo para mis estudiantes de norma general excluyente de carácter prohibitivo. Al cabo del tiempo encontré uno meramente literario en las memorias de Koestler cuando cuenta que «dentro de la vida normal, se permite todo lo que no está prohibido por la ley. En mi infancia, se prohibía todo lo que no estaba expresamente permitido» (A. Koestler 1973, p. 45). Recientemente un abogado amigo me facilitó un ejemplo real, de mínima importancia pero muy gráfico. Se trataba del Reglamento Técnico del Campeonato de España de Fórmula Renault de 1997 (una competición deportiva de carácter federativo oficial) que contenía una cláusula preliminar del siguiente tenor: «Todo aquello que no 
no de los hechos, que un ordenamiento jurídico no garantice efectivamente este principio general de libertad. En ambos casos se estaría negando la autonomía como carácter moral originario de los sujetos de tales sistemas y, por ello, su condición humana de agentes morales. ${ }^{18}$

Isaiah Berlin teorizó genialmente la vieja distinción de Constant entre dos formas de libertad: la libertad negativa y la libertad positiva (Constant [1819] 1988 y Berlin 1974). ${ }^{19}$ Sin embargo dejó sumida en la confusión la relación entre ambas. Insistió mucho, como es sabido, en que se trataba de dos cosas distintas y llegó a concluir que «no hay una conexión necesaria entre la libertad individual y el gobierno democrático» (Berlin 1974, p. 227). La libertad negativa consiste, en términos de Berlin, en poder actuar sin obstrucciones de otros; la libertad positiva consiste, según él, en que quiero ser mi propio amo (ibidem, pp. 217 y 229). Lo que Berlin niega insistentemente es que sean la misma cosa. Creo que en cierto modo se equivocó. Libertad negativa y libertad positiva son dos posiciones normativas distintas pero ambas consisten en el ejercicio de la autonomía individual, si bien en diferentes contextos. La autonomía se puede ejercer individualmente en multitud de aspectos con el sólo limite de la igual libertad ajena. La autonomía, sin embargo, no puede ejercerse individualmente en aquellos ámbitos en que las decisiones son interdependientes. Con un ejemplo sencillo: yo puedo decidir con perfecta autonomía si esta tarde voy al cine o al teatro. Pero si mi decisión individual autónoma es pasar la tarde con mi mujer y mis dos hijos, y sus tres decisiones individuales autónomas son recíprocamente iguales, entonces la decisión de qué hacer aparece como una decisión de segundo orden que ha de tomarse en situación de interdependencia. No es ya posible que ninguno de los cuatro decidamos individual y

esté expresamente autorizado en este Reglamento, en el Manual de Reparación [...] entregado a cada piloto inscrito en el campeonato, en los boletines técnicos susceptibles de ser difundidos [...] durante la temporada 1997: está prohibido.»

${ }_{18}$ En este mismo sentido se pronuncia Rawls (1990, p. 34): «Hay, ciertamente, una presunción general contraria a la imposición de restricciones a la conducta-legales o de otro tipo- sin una razón suficiente. Pero esta presunción no determina una prioridad especial a ninguna libertad en particular.»

${ }_{19}$ Por lo que respecta a la idea de una tercera forma de libertad, la libertad real o libertad como capacidad, creo - con Berlin, Aron y Laporta, entre otros- que se trata de una idea errónea pues una cosa es la libertad y otra las condiciones para ejercerla (por todos, Laporta 1983, pp. 29-31) aunque tales condiciones «afectan a la valía de la libertad», como señala Rawls (1990, p. 71). En consecuencia distingo sólo dos formas de libertad: la libertad negativa entendida como ámbito de actuación no interferido por actos ajenos ni por normas y la libertad positiva entendida como participación en la elaboración de las normas (Laporta 1983, p. 32). Laporta, siguiendo a Berlin, admite que no hay implicaciones lógicas entre una y otra aunque sí afirma -contra Berlin- las implicaciones políticas entre ambas. Por mi parte trato de demostrar que tales implicaciones son mucho más fuertes, en el sentido de que tanto la libertad negativa como la libertad positiva expresan y realizan el mismo valor moral (el de la autonomía personal) en diferentes contextos de decisión por lo que la satisfacción de la autonomía personal requiere simultáneamente el reconocimiento de la libertad negativa y de la libertad positiva (vid. Gewirth 1990, p. 137). 
autónomamente qué hacer si queremos satisfacer nuestra preferencia primaria de pasar la tarde juntos. La alternativa berliniana parece obligarnos a abandonar el ámbito de la libertad individual negativa y entrar en un contexto que no tiene ninguna conexión «necesaria» con él; esto es lo que ocurriría si, ante la nueva situación, decidimos que la autonomía es inviable y que, por ello, debe decidir el cabeza de familia, o el suegro (dado su particular carisma), o el azar (por ser más igualitarios). Ninguna de las tres soluciones respeta la autonomía de nadie salvo la primera que sólo respeta la autonomía de uno. Pero esta alternativa es falsa. Si creamos un contexto que permite a los cuatro exponer sus razones, tratar de convencer a los demás, y -caso de no llegar a un consenso- decidimos por mayoría, entonces hemos permitido el mayor ejercicio posible de la autonomía individual de cada uno de los cuatro en esa situación de interdependencia. Naturalmente el problema se vuelve simplemente más trágico si la situación de interdependencia no es voluntaria sino necesaria pero el escenario es el mismo, y la respuesta es precisamente el escenario de la libertad positiva. No en vano la teoría de la democracia nació de representar la vida en sociedad como si se tratase de una interdependencia voluntaria, es decir de un «contrato social». La libertad positiva no es, por tanto, otra cosa que el ejercicio de la autonomía personal en condiciones de interdependencia.

Si unimos esta conclusión a la inmediatamente anterior podremos concluir fácilmente que la libertad como derecho humano implica un principio de conservación de la libertad general que puede enunciarse así: no ha de someterse al escenario de la libertad positiva ningún ámbito de la acción de una persona que no requiera decisiones interdependientes.

Hay un último rasgo relativo a la libertad que merece una referencia. Se trata del carácter cualitativo de la libertad que puso de relieve John Mackie (Mackie 1984, p. 178). El valor de la libertad no depende de la cantidad de conductas permitidas menos la cantidad de conductas obligatorias y prohibidas, sino de la cualidad de las unas y las otras. Hay ámbitos de la acción inmediatamente vinculados con el desenvolvimiento de la persona como agente moral, como el ámbito de las creencias, de las convicciones, de las preferencias internas, de la comunicación, de la elaboración de planes de vida, etc. y ámbitos muy distantes de esa cualidad moral, como las costumbres, las modas, las preferencias externas, etc. Aunque para mí fumar se ha convertido en una mala costumbre muy arraigada y probablemente no fumar me haría transitoriamente poco feliz, no tendría sentido afirmar que, existiendo alguna razón relevante de coordinación social como la salud ajena o el gasto sanitario, una norma que me prohibiese fumar me limitaba como agente moral. Ese carácter cualitativo es el que obliga a convertir determinados ámbitos de la libertad general en inmunidades frente a la propia voluntad mayoritaria (Rawls 1990, pp. 88 y 115).

El derecho a la libertad o, por mejor decir, la libertad como derecho moral básico podría, en consecuencia, enunciarse en estos términos: 
(2) Todo ser humano tiene derecho al conjunto de libertades necesarias para desenvolverse como agente moral así como un derecho general a que su libertad de acción sólo sea limitada por razones necesarias de coordinación social y mediante su consentimiento directo o representado.

\subsection{El derecho a la igualdad}

El derecho a la igualdad, esto es a ser tratado con la misma consideración y respeto, deriva asimismo de forma necesaria de la atribución de valor moral a las personas por su igual condición de agentes morales. La igualdad reviste también dos formas que solemos denominar como igualdad ante la ley (o igualdad formal) e igualdad en las oportunidades o en la satisfacción de necesidades básicas o en las capacidades (o igualdad material). En el caso de la igualdad parece que también nos encontramos ante dos formas distintas. La igualdad formal se reduciría básicamente a la inmunidad frente a tratamientos discriminatorios del legislador que se vería así privado de competencia normativa para discriminar. La igualdad material, por su parte, consistiría en la pretensión de obtener una cierta cantidad de prestaciones en alimento, sanidad, condiciones de vida, educación, información, y capacitación para desenvolver la propia autonomía en similares condiciones de partida; consiste -podríamos decir- en disponer de un conjunto equitativo de condiciones para ejercer la libertad. La idea poco afortunada de «libertad real» (o «libertad material») se remite en realidad a esta idea de condiciones equitativas para ejercer la libertad (vid. supra nota 19). Sin embargo tanto la igualdad formal como la igualdad material son expresión de la misma idea normativa de que cualquier ser humano tiene el mismo valor moral que cualquier otro.

El gran problema de la igualdad, sin embargo, quedó perfectamente planteado desde Aristóteles y estriba en que la idea misma de igualdad es comparativa y requiere por ello tratar igualmente a lo que es igual y desigualmente a lo que es desigual. Para formularlo en los términos en que Bobbio lo ha dejado planteado el problema de la igualdad permite cuatro respuestas: «tratar igualmente» a todos en todo, a todos en algo, a algunos en todo o a algunos en algo (Bobbio 1993, p. 83). La primera incógnita parece hoy despejada. Como señaló Peter Singer «el principio de que todos los seres humanos son iguales es hoy parte de la ortodoxia ética y política dominante» (Singer 1984, p. 28), pero parece importante destacar que tras la constatación de este bienaventurado dato de nuestra moralidad positiva se halla una «verdad» ética o, por decirlo más correctamente, una exigencia de la racionalidad ética que se deriva de la universalización de la dignidad última que yo mismo me atribuyo como agente moral y que, por ello, he de reconocer a todo agente moral. Se abre aquí, por supuesto, el problema de los infantes (es decir, los que todavía no se expresan) y de los seres humanos que no han alcanzado o han perdido la agencia moral (digamos llanamente que «no son personas»), problema del que en este momento no me 
ocuparé, aunque me he ocupado parcialmente, respecto a los niños, en otros momentos (Hierro 1991, 1996 y 1999).

Respecto a la segunda incógnita puede constatarse que cualquier pretensión de igualdad en todo -lo que suele denominarse de igualdad en resultados- resulta contradictoria con la idea de autonomía moral del agente y su consiguiente responsabilidad. Sólo si hacemos tabla rasa de la responsabilidad moral del agente podemos redistribuir a todos y cada uno la misma cantidad de bienes o de bienestar. El propio respeto a la autonomía moral requiere, por lo tanto, una igualdad en las oportunidades que por su propio sentido implica un desigual tratamiento de sus necesidades $y$, posteriormente, un desigual tratamiento de sus desiguales aptitudes y méritos. El respeto de la autonomía personal más el respeto del igual valor moral de cada uno nos obliga a adoptar un principio general de igualdad de oportunidades que en otro lugar he enunciado de esta forma: «nuestro ideal de igualdad es la igualdad entre todos los seres humanos en los recursos adecuados para satisfacer las necesidades básicas, de forma que permitan a todos y cada uno desarrollar de forma equiparablemente autónoma y libre su propio plan de vida» (Hierro 1995, p. 137), pero al mismo tiempo nos obliga a utilizar criterios relevantes de tratamiento desigual en diferentes esferas (Walzer 1993) ${ }^{20}$. Este doble principio se traduce, según creo, en un enunciado del contenido básico del derecho a la igualdad en los términos siguientes:

(3) (3.1) Todo ser humano tiene derecho a un igual trato legal y a unas iguales oportunidades para desenvolverse como agente moral. (3.2) La diferenciación por rasgos distintivos relevantes sólo procede cuando la no discriminación por rasgos irrelevantes está satisfecha. (3.3) La diferenciación en resultados sólo procede cuando la igualdad en oportunidades está satisfecha. (3.4) Una sociedad, sus normas e instituciones, satisfacen el derecho a la igualdad cuando sus posiciones y bienes están abiertos a todos en virtud del principio de no discriminación y de igualdad de oportunidades y sólo establece tratos desiguales en virtud de criterios relevantes y adecuados al caso, a saber: (3.4.1) el criterio de necesidad vale para diferenciar en la igualación de oportunidades y en la redistribución de resultados; (3.4.2) el criterio de mérito vale para atribuir premios, recompensas y castigos a las acciones voluntarias y en la atribución de resultados; (3.4.3) el criterio de aptitud vale para atribuir cargos y funciones que no sean representativas; (3.4.4) el criterio de status vale sólo si es reducible a algu-

${ }^{20}$ La gran aportación de Walzer es, en mi opinión, la demostración de que la igualdad es un valor complejo que requiere la utilización de criterios diferentes para esferas diferentes. Sin embargo me parece que «Las esferas de la Justicia» adolece de una demostración mínimamente sistemática de cuáles son las razones que sustentan el criterio que debe regir en cada esfera, defecto que, con toda seguridad, es el precio del «comunitarismo» de Walzer que le conduce a una conclusión tan desilusionante como ésta: «Así como es posible describir un sistema de castas que cumpla con los parámetros (internos) de la justicia, es posible describir un sistema capitalista que cumpla con la misma finalidad» (Walzer 1993, p. 324). 
no de los anteriores, e incluye la discriminación inversa en función de la igualación en oportunidades. ${ }^{21}$

\subsection{El derecho a la seguridad}

Respecto a la seguridad se repite una vez más el inevitable dualismo. Distinguimos habitualmente dos diferentes aspectos de la seguridad: la seguridad jurídica y la seguridad frente al riesgo. En este caso, sin embargo, no creo que ambos aspectos se refieran a o manifiesten un mismo derecho moral básico. El derecho a la seguridad jurídica es una necesidad derivada de la autonomía. Se trata de una inmunidad frente a la arbitrariedad y se traduce en los requerimientos para que la persona y la libertad personal estén garantizadas normativamente frente a la acción ajena (como en el mal llamado «derecho a la vida» que en realidad es un derecho a «conservar» la vida, o en el derecho a la integridad física, etc.) así como en que los límites a la libertad personal están establecidos por normas generales, preestablecidas, irretroactivas, públicas y eficaces, lo que ha desplegado toda su virtualidad en la institucionalización del «rule of law» o «imperio de la ley» en sentido estricto (Laporta 1994). Más problemático parece cómo situar el segundo aspecto de la seguridad cuando éste se entiende como un derecho «social» o de segunda generación a prestaciones en caso de sucesos más o menos azarosos como la enfermedad, el desempleo, la incapacidad, etc. Creo que claramente este aspecto de la seguridad se ha de situar en uno de los renglones del derecho a la igualdad, esto es en la redistribución desigualitaria de resultados en virtud del criterio de necesidad.

Si esto es así, como pienso, el derecho a la seguridad podría enunciarse a su vez en la siguiente forma:

(4) Todo ser humano tiene derecho a la protección normativa de su vida, su integridad física y moral y su libertad de acción frente a la acción ajena y a que los límites de su libertad estén establecidos por reglas generales claras, preestablecidas, públicas, irretroactivas y eficaces.

\section{Derechos morales, derechos constitucionales y derechos universales}

Algunos autores han señalado la paradoja de que unos derechos que se predican como universales en el sentido de que moralmente hablando co-

${ }^{21}$ «Sólo procede» debe entenderse aquí como una aserción en el plano moral; significaría que «sólo tiene un justificación moral completa». Por supuesto la imperfección de las estructuras sociales reales y la dinámica de la realidad hacen imposible cualquier pretensión de suspender toda diferenciación en resultados (en razón del mérito) hasta que haya una perfecta igualdad de oportunidades. Lo que el principio expresa es que tal diferenciación en resultados no tendría una justificación moral completa en tanto en cuanto no se diera una perfecta igualdad de oportunidades. No parece inútil tener claro quiénes son moralmente los deudores y quiénes los acreedores en una sociedad en la que no se haya podido llegar a cancelar toda discriminación por rasgos irrelevantes y/o no se haya podido satisfacer perfectamente la igualdad de oportunidades. 
rresponden a todos y cada uno de los seres humanos hayan de satisfacerse por ordenes jurídicos particulares. Otros, de forma más sofisticada, han sostenido que los derechos morales básicos son derechos «prima facie» cuya realización normativa exige un proceso de institucionalización que los convierta en derechos finales y que en ese proceso puede haber decisiones consensuadas de segundo orden que contextualizan estos derechos. ${ }^{22}$ El denominado proceso de positivación parecería ser la respuesta histórica a esa necesidad de concretar en forma jurídica aquellos derechos morales (Pérez Luño 1984, Capítulo 2), y el denominado proceso de internacionalización parecería responder a la necesidad de institucionalizar a nivel supranacional la referencia y el control de tales procesos de positivación en los ordenamientos jurídicos internos (ibidem, p. 82 y Peces Barba 1991, p. 153). Esta parece que fue, en efecto, la inmensa aportación de la Declaración Universal que recientemente hemos conmemorado: institucionalizar unas ideas morales en forma de moralidad política positiva y apuntar algunos instrumentos de control. Pero no es este aspecto del pasado histórico del que ahora quiero ocuparme, sino de las posibilidades que ofrece el futuro. En otro lugar he planteado con más detalle el que me parece problema fundamental de la universalización de los derechos (Hierro 1995), que es el siguiente: mientras la libertad y la seguridad son condiciones que normativamente un sujeto puede tener o no tener reconocidas y garantizadas, o tener reconocidas y garantizadas en mayor o menor grado, la igualdad es tanto en su aspecto formal como en su aspecto material una cualidad o un tratamiento comparativo. Lo que significa esta diferencia conceptual -que Bobbio puso

${ }^{22}$ Que los derechos humanos son derechos «prima facie» es algo que se afirma con frecuencia pero al menos en dos sentidos diferentes. Unas veces quiere decirse que no son derechos «absolutos» porque pueden entrar en conflicto y, si bien se consideran como «triunfos» a priori frente a otros valores o preferencias, ello no resuelve el problema cuando el conflicto es entre derechos humanos; en tal caso se requiere siempre una ponderación y un derecho (es decir, su satisfacción) puede tener que ceder total o parcialmente ante otro (Gewirth1984, p. 92 donde divide la infracción de los derechos en violación, como infracción injustificable, e invalidación (overriding), como infracción justificable. Vid. también Laporta 1987, pp. 40-41). En este sentido la idea de derechos «prima facie» se opone a la de derechos «absolutos». Otras veces quiere decirse que los derechos humanos o «fundamentales» requieren compromisos institucionales para convertirse en derechos «finales». Estos compromisos sirven también para equilibrar las tensiones entre unos derechos y otros (Mackie 1984, p. 177) pero son en todo caso necesarios para convertir los derechos morales abstractos en derechos constitucionales concretos bajo cuya forma «final» los derechos son normalmente «complejos» de pretensiones, libertades, inmunidades y potestades (Scanlon 1984, p. 139). Piénsese, por ejemplo, en la libertad positiva que es, en abstracto, una «potestad» y se manifiesta -entre otras cosas- en el derecho al sufragio cuya institucionalización implica la potestad de votar con fuerza decisoria, la libertad de elegir entre varias opciones, ciertas inmunidades (p.ej. el secreto del voto) y un sinfín de pretensiones frente al Estado (que convoque elecciones, realice censos, publique listas, establezca colegios, etc. etc.). Por otra parte los compromisos institucionales pueden configurar de muchas formas admisibles la periodicidad electoral, el sistema de demarcaciones, el carácter abierto o cerrado de las listas, etc. etc. En este sentido la idea de derechos «prima facie» se opone a la de derechos «finales». 
de relieve con su habitual claridad (Bobbio 1993, p. 54)- es que en un mundo ideal pero posible en el que todos los Estados reconociesen y protegiesen efectivamente la libertad y la seguridad de sus ciudadanos todos los hombres podrían ver satisfechos ambos derechos morales. Pero, sin embargo, ello no parece posible respecto a la igualdad. En su aspecto formal porque la propia estructura del Estado exige distinguir en algo a sus nacionales de los extranjeros y esta diferencia necesaria parece ser particularmente exigente respecto a la propia definición de nacional y de extranjero y por ello a la cualidad de «miembro» de la comunidad política (Walzer 1993, p. 44); en su aspecto material porque el ámbito de los nacionales parece ser el que define en sentido ético, político y jurídico el número de los candidatos a ser tratados igualmente ${ }^{23}$, a disponer de una igualdad de oportunidades y a disfrutar por ello de una redistribución de los resultados. El horizonte de una igualdad entre todos los seres humanos parece exigir, por ello, una especie de ciudadanía universal que -como en el caso de la construcción europeaimplica enseguida una caída de las fronteras y una libertad de movimientos que redujera la nacionalidad a un rasgo irrelevante así como una especie de igualación universal de las oportunidades mediante una redistribución universal de los recursos. Alguien ha dicho con autoridad que este panorama nos conduce a magnitudes inconmensurables que exceden nuestro horizonte ético (Fishkin 1986). Alguien más cercano a nosotros, a quien ya cité cuando me ocupé de esta cuestión, ha contestado: «una cosa es la incapacidad de nuestro razonamiento práctico para alumbrar una posición moral coherente y otra muy distinta nuestra escasa disposición a aceptar un principio moral que quiebra nuestra buena conciencia y exige un serio sacrificio de nuestros intereses» (Bayón 1986, p. 54).

\section{El orden nominal de los derechos y la nómina de los derechos}

En un esbozo -como pretende ser éste- de una «Teoría de los Derechos Humanos» han quedado necesariamente fuera infinidad de problemas. Pero hay al menos dos que tienen un carácter central para responder la pregunta que al principio quedó planteada. Se trata, en primer lugar, de saber si entre la libertad, la igualdad y la seguridad hay una relación jerárquica de algún tipo que, de haberla, sirviera también como criterio de solución de los con-

${ }^{23}$ En Hierro 1995, p. 147, decía yo que el Estado se convertía en el ámbito de realización de la igualdad y que ello tenía tres graves consecuencias: una ideológica o epistémica al definir el ámbito de los iguales como el de los nacionales; una ética al cerrar en el nivel del Estado el ámbito de institucionalización de nuestros deberes y una jurídica al delimitir del mismo modo lo jurídicamente exigible. Atienza apuntaba, entre otras críticas, que la segunda consecuencia sólo vale en relación con cierta moral social pero no respecto a una moral crítica (Atienza 1997, p.21). Tiene toda la razón. Cuando señalé aquellas tres consecuencias, que califiqué de graves, me refería a consecuencias que se producen en la ideología dominante, en la moralidad positiva dominante y en los ordenamientos jurídicos positivos en relación con el Derecho Internacional en su estado actual. Creo que se deduce muy obviamente del contexto. 
flictos entre derechos. Una ordenación lexicográfica entre el principio de libertad y el principio de igualdad ha sido defendida por Rawls (Rawls 1971, pp. 61, 89, 244, 301 y 302) y sería sencillamente aplicable al enunciado de estos dos principios de justicia como derechos morales. Como es sabido Rawls propone dos reglas de prioridad (Rawls 1971, pp. 302-303). Conforme a la primera de ellas, los principios de justicia -yo traduciría ahora: los derechos humanos- han de ser jerarquizados en un orden léxico en virtud del cual la libertad sólo puede ser restringida en aras de la libertad; conforme a la segunda, la justicia es previa a la eficiencia, y la igualdad de oportunidades es previa al principio de diferencia (ibidem). Puesto que creo haber incluido ya esta segunda parte de la segunda regla de prioridad en la definición propuesta del derecho a la igualdad, me referiré ahora sólo y brevemente a la primera regla de prioridad y a la primera parte de la segunda.

La primera parece establecer una prioridad de la libertad y, como consecuencia, que la libertad sólo puede limitarse en aras de ella misma. Amartya Sen ha tratado de encontrar una argumentación empírica a favor de esta misma tesis demostrando que no hay ejemplos reales en que la limitación de la libertad se traduzca en una condición necesaria para incrementar la igualdad o la riqueza (Sen 1995, pp. 207-209). Sólo quiero ahora señalar que estas tesis, que comparto, sólo son sostenibles una vez que uno ha extraído del derecho a la libertad lo que, en su preciso origen, se sostuvo como su manifestación primaria, es decir la propiedad privada de bienes productivos. Una vez dado este paso es correcta -creo- la ordenación nominal. La libertad es previa y sólo debe ser limitada en aras de la igual libertad de cada uno. Este orden no hace sino reproducir el orden de fundamentación de los derechos a partir de la idea normativa de la persona como agente libre y, por ello, moral. ${ }^{24}$

La primera parte de la segunda regla, esto es la prioridad de la justicia sobre la eficiencia, nos sitúa en el último de los problemas a los que quería hacer referencia, es decir: la posibilidad de cerrar la nómina de los derechos morales básicos. He sostenido ya en otro lugar que en cierto sentido esto no es posible (Hierro 1998). No lo es en la medida en que las necesidades del sujeto para desenvolverse como agente moral son necesidades relativas al

${ }^{24}$ Requeriría una discusión mucho más extensa qué conclusiones se derivan del orden lexicográfico propuesto por Rawls ya que él mismo admite que la estricta exigencia derivada de tal ordenación léxica (es decir que « this is an order which requires us to satisfy the first principle in the ordering before we can move on to the second, the second before we consider the third, and so on» (Rawls 1971, p. 43) sólo es aplicable en una sociedad bien ordenada y bajo circunstancias favorables (ibidem, p. 245). En condiciones no ideales, esto es dadas ciertas limitaciones naturales o ciertas contingencias históricas, el orden léxico es sólo una guía o un «equilibrio a largo plazo» que puede requerir ajustes (ibidem, pp. 246 y 247: «To accept the lexical ordering of the two principles we are not required to deny that the value of liberty depends upon circunstances»). Como ha señalado posteriormente Rawls la «división de papeles entre los dos principios de justicia no es sino parte de un marco orientador de la deliberación» (Rawls 1996, p. 406). 
contexto. Rawls las ha denominado «bienes primarios» y ha dicho que son «condiciones necesarias para realizar las facultades de la personalidad moral» (Rawls 1986, pp. 193-194 y Rawls 1996, pp. 222-224) ${ }^{25}$ y ha incluido entre ellos las libertades negativas y positivas y ciertos niveles de renta, riqueza y autoestima. Creo que todos los bienes primarios básicos, en sentido rawlsiano, se corresponden con los derechos morales básicos, esto es las libertades e inmunidades que constituyen el ámbito de la libertad negativa, las potestades, libertades y pretensiones de participación que constituyen el ámbito de la libertad positiva, y las pretensiones a prestaciones que aseguren las capacidades para desenvolverse que constituyen el ámbito del derecho a la seguridad y de los derechos llamados económico-sociales y, muy particularmente, el último renglón de Rawls, donde se refiere a las bases sociales del respeto de uno mismo lo que parece constituir el ámbito de la igualdad como derecho (Rawls 1986, p. 190 y Rawls 1996, p. 214 y 356). Lo que esto exige no es una igualdad en los resultados, en el bienestar, en la renta o en la riqueza; lo que requiere tan sólo es una igualdad en la satisfacción de las necesidades o derechos básicos que permitan a todas las personas desenvolverse como agentes morales en un contexto dado pero implica, a su vez, una desigualdad en le redistribución de recursos para compensar desventajas de carácter natural o social (lo que Dworkin ha llamado desventajas en las dotaciones) (Dworkin 1981, p. 299). Pues bien, si pudiésemos establecer cuál es ese mínimo básico de necesidades que deben ser satisfechas, o incluso más relativamente el mínimo básico en una sociedad de riqueza y capacidad productiva determinadas, entonces este renglón de la Justicia como satisfacción de los derechos sólo requeriría que todos y cada uno tuviesen satisfecho tal mínimo. Pero resulta que si -continuando el argumento de Rawls- la auotestima depende de ciertas bases sociales que permitan a cada uno ser un miembro cooperador normal de la sociedad en que vive, entonces las necesidades mínimas que han de ser satisfechas, desde el aporte diario de calorías hasta el nivel de educación, son una construcción social que es función de las posibilidades de satisfacción en un contexto dado, es decir que cada uno experimenta como una necesidad básica aquello que, si hubiese sido tratado con igual consideración, hubiera podido llegar a alcanzar en su contexto. La conclusión es entonces que no es posible establecer un mínimo fijo como medida de la justa satisfacción de las necesidades del sujeto como agente moral sino que este mínimo se ve arquimédicamente empujado hacia la posición de los que más han alcanzado y entonces la igualdad como derecho requiere movimientos redistributivos constantes. Esto significa que aunque podamos cerrar nominalmente el catálogo de los derechos humanos no podemos llegar a cerrar la cantidad y calidad de los bienes necesarios para satisfacer esos derechos. Que los de-

\footnotetext{
${ }^{25}$ Una teoría sistemática de las necesidades puede verse en Doyal y Gough 1994.
} 
rechos o, por así decirlo, su contenido se expanden al mismo ritmo al que se expande la riqueza material y cultural de una sociedad. ${ }^{26}$

Y me resta añadir, aunque no lo desarrollaré ahora, que en mi opinión un orden lexicográfico de los derechos debiera empezar por el derecho a la seguridad en los términos en que lo he definido con lo cual, y aunque esta no sea obviamente la razón para hacerlo, Hobbes recuperaría el lugar que le corresponde en la historia de los derechos humanos. ${ }^{27}$

\section{Conclusión frente a algunas objeciones}

De las muchas objeciones que sin duda pueden oponerse a un esbozo teórico como éste quisiera afrontar, como conclusión, las dos que me parecen más relevantes. La primera es la objeción de que una teoría moral normativa pueda basarse exclusivamente en los derechos. Joseph Raz ha demostrado, entre otros, que una moral basada en derechos sólo puede defenderse como una moral «estrecha» que se limite a «incluir sólo todos aquellos principios que restringen la prosecución del individuo de sus objetivos personales y su fomento de su propio interés» (Raz 1984, p. 198). La objeción, en este aspecto, me parece totalmente admisible porque una Teoría de los Derechos Humanos puede constituir, según creo, una teoría completa de la Justicia pero no un diseño completo del ideal de vida buena.

La segunda objeción viene, sin embargo, estrechamente derivada de la anterior y es una objeción que crece, o renace, amenazadoramente en la última década. Se trata de la objeción anti-individualista que ha tomado cuerpo en las posiciones comunitaristas. ${ }^{28}$ Sin duda alguna una Teoría de los Derechos es individualista en el nivel metodológico aunque no lo es, necesariamente, en sus consecuencias políticas y jurídicas; más bien sería todo lo contrario porque, en los términos aquí planteados, conduce a requerimientos fuertes de organización, cooperación y redistribución. Ello no obstante, uno de los argumentos centrales del comunitarismo pretende que el individualismo metodológico que fundamenta la Teoría de los Derechos y el igualitarismo liberal que de ella se deriva, así como sus pretensiones de universalidad, son sólo una imposición eurocéntrica (hoy, yanquicéntrica) sobre la diversidad de modelos culturales que configuran las muy diversas formas de ser-individuo-humano: una especie, al fin y al cabo, de colonialismo cultural y, por ello, una negación del auténtico universalismo. Prescindiendo ahora del pequeño detalle de que el comunitarismo sea tan occidental (y tan yanqui) como este igualitarismo liberal, cabe una contestación. Uno de los

\footnotetext{
${ }^{26}$ He desarrollado estas ideas con algo más de detalle en Hierro 1998, pp. 168-177.

${ }^{27}$ Además del denominado derecho a la vida y del derecho a la integridad física y moral, la propia seguridad jurídica aparece entonces como una necesidad primaria de la autonomía personal (vid. Laporta 1994, passim y Hierro 1996 (2), pp. 288-290).

${ }_{28}$ Vid. una exposición general del problema en A. Ruiz Miguel, Derechos humanos y comunitarismo. Aproximación a un debate, Doxa 12, 1992, pp. 95-114.
} 
problemas que el comunitarismo comparte con su pariente próximo, el nacionalismo, es el de delimitar el ámbito de la comunidad relevante para establecer las identidades y las decisiones colectivas. Hay religiones, y comunidades dentro de las religiones, y sectas dentro de las comunidades... Hay naciones-estado, y grupos nacionales dentro de ellas, y comunidades locales dentro de ellas... Y así sucesivamente. Pues bien, una de las características del mundo configurado tras la Segunda Guerra Mundial es su progresiva integración económica, política, comunicativa y cultural. Y en este mundo integrado a nivel universal todos los países han suscrito de mejor o peor grado una Declaración Universal de Derechos Humanos -cuyo cincuenta aniversario acabamos de conmemorar- que es básicamente esta concepción liberal igualitaria de las condiciones políticas del bienestar humano y que precisamente se expresa como «declaración de derechos». Siendo esto así resulta que nuestro nivel más amplio de comunidad -la comunidad universal humana- comparte hoy una concepción que delimita nuestras opciones sobre el bien político y, por ello, cualquier comunitarista consecuente debiera admitir que, a fuer de comunitarista, no tiene otro remedio que asumir como propia, como parte constitutiva de su propia identidad cultural, precisamente esta concepción liberal igualitaria que se encierra en la Declaración Universal de Derechos Humanos.

\section{Referencias bibliográficas}

Alexy, Robert: 1993 Teoría de los derechos fundamentales, Centro de Estudios Constitucionales, Madrid. (Orig: Theorie der Grundrechte, Suhrkamp, Berlin, 1986).

- 1995 Discourse Theory and Human Rights, en Varios 1995 (Tomo II), pp. 2228.

Atienza, Manuel: 1986-7 Una clasificación de los derechos humanos, Anuario de Derechos Humanos 4, pp. 29-43.

- 1997 Los límites de la interpretación constitucional. De nuevo sobre los casos trágicos, Isonomía 6, Abril 1997, pp. 7-30.

Bayón, Juan C.: 1986 Los deberes positivos generales y la determinación de sus límites, Doxa 3, pp. 35-54.

Berlin, Isaiah: 1974 Dos conceptos de libertad, en Quinton 1974, pp. 216-233.

Betegón, Jerónimo y Páramo, Juan R. (edits.): 1990 Derecho y Moral. Ensayos analíticos, Ariel, Barcelona.

Bobbio, Norberto: 1991 El tiempo de los derechos, Sistema, Madrid.

- 1993 Igualdad y Libertad, Paidós/ICE-UAB, Barcelona. (Orig: Equaglianza-Libertá, voces en la Enciclopedia del Novecento, vol. II, pp. 355-364 y vol. III, pp. 994-1004, Istituto dell'Enciclopedia Italiana, Roma, 1977 y 1979).

Bodino, Jean: 1973 Los seis libros de la República, selección de P. Bravo, Aguilar, Madrid, (Original de 1576).

Castignone, Silvana: 1996 Nuovi diritti e nuovi soggetti, Edizioni Culturali Internazionale Genova, Genova. 
Constant, Benjamin: 1988 Del espíritu de conquista (y De la libertad de los antiguos comparada con la de los modernos), Tecnos, Madrid, (Original de 1819).

Doyal, Len y Gough, Ian: 1994 Teoría de las necesidades humanas, Fuhem/Icaria, Madrid. (Orig: A Theory of Human Needs, Tha MacMillan Press, Londres, 1991).

Dworkin, Ronald: 1981 What is Equality? Part 2. Equality of Resources, Philosophy and Public Affairs 10, pp. 283-345.

- 1984 Los derechos en serio, Ariel, Barcelona. (Orig: Taking Rights Seriously, Gerald Duckworth \& Co., Londres, 1977).

Feinberg, Joel: 1980 Rights, Justice and the Bounds of Liberty, Princeton University Press, Princeton (NJ).

Fernández, Eusebio: 1984 Teoría de la Justicia y Derechos Humanos, Debate, Madrid.

Fishkin: 1986 Las fronteras de la obligación, Doxa 3, pp. 69-82.

Gewirth, Alan: 1984 Are there any Absolute Rights?, en Waldron 1984, pp. 91-109.

- 1990 La base y el contenido de los derechos humanos, en Betegón-Páramo 1990, pp. 125-145. (Orig: The Basis and Content of Human Rights, Nomos XXIII, New York University, New York, 1981)

Grocio, Hugo: 1987 Del derecho de presa. Del derecho de la guerra y de la paz, selección de P. Mariño, Centro de Estudios Constitucionales, Madrid, (Original de 1625).

Hart, Herbert L.A.: 1982 Essays on Bentham. Studies in Jurisprudence and Political Theory, Clarendon Press, Oxford.

Hierro, Liborio L.: 1982 ¿Derechos humanos o necesidades humanas? Problemas de un concepto, Sistema 46, pp. 45-61.

- 1991 ¿Tienen los niños derechos? Comentario a la Convención sobre los Derechos del Niño, Revista de Educación 294, Enero-Abril 1991, pp. 221-233.

- 1995 Las huellas de la desigualdad en la Constitución, en Mate 1995, pp. 131150.

- 1996 Los derechos de la infancia. Razones para una ley, en Estudios jurídicos en homenaje al Prof. Aurelio Menéndez, Civitas, Madrid, vol. IV pp. 5473-5493.

- 1996 (2) El imperio de la ley y la crisis de la ley, Doxa 19, pp. 287-308.

- 1998 Justicia, igualdad y eficiencia, Isonomía 9, pp.129-171.

- 1999 Il bambino e i Diritti dell uomo, Materiali per una Storia della cultura giuridica XXIX, Junio 1999, pp. 189-205.

Hohfeld, Wesley N.: 1913 Some fundamental legal conceptions as applied to judicial reasoning, Yale Law Journal 23, (hay traducción española: Conceptos jurídicos fundamentales, Centro Editor de América Latina, Buenos Aires, 1968).

Kant, Inmanuel: 1978 Introducción a la Teoría del Derecho, Centro de Estudios Constitucionales, Madrid, (Original de 1797).

Koestler, Arthur: 1973 Flecha en el azul, Alianza, Madrid.

Laporta, Francisco: 1983 Sobre el uso del término «libertad» en el lenguaje político, Sistema 52, pp. 23-43.

- 1987 Sobre el concepto de derechos humanos, Doxa 4, pp. 23-46.

- 1987 (2) Respuesta a Pérez-Luño, Atienza y Ruiz Manero, Doxa 4, pp. 71-77. 
- 1994 Imperio de la ley. Reflexiones sobre un punto de partida de Elías Díaz, Doxa 15-16, vol. 1 pp. 133-145.

Mackie, John L.: 1984 Can There be a Right-based Moral Theory?, en Waldron 1984, pp. 168-181.

Mate, Manuel-Reyes (edit.): 1995 Pensar la igualdad y la diferencia. Una reflexión filosófica, Argentaria/Visor, Madrid.

Matsuo, Hiroshi: 1995 Historical and Theoretical Intimacy between the Concepts of Rights and Property, en Varios 1995 (Tomo III), pp. 11-17.

Paine, Thomas: 1986 Los Derechos del Hombre, Fondo de Cultura Económica, México, (Original de 1791-92).

Páramo, Juan R.: 1986-7 El concepto de «derecho»: una introducción bibliográfica, Anuario de Derechos Humanos 4, pp. 199-218.

- 1996 Derecho subjetivo, en El Derecho y la Justicia. Enciclopedia Iberoamericana de Filosofía 11, edición de E. Garzón Valdés y F. J. Laporta, Trotta, Madrid, 1996, pp. 367-394.

Peces-Barba, Gregorio: Derechos fundamentales, Latina, Madrid.

- 1991 Curso de derechos fundamentales I (Teoría General), Eudema, Madrid.

- 1995 Los derechos humanos ante los problemas clásicos de la Filosofía del Derecho, en Varios 1995 (Tomo II), pp. 183-192.

Pérez-Luño, Antonio E.: 1984 Derechos humanos, Estado de Derecho y Constitución, Tecnos, Madrid.

1987 Concepto y concepción de los derechos humanos. Acotaciones a la Ponencia de Francisco Laporta, Doxa 4, pp. 47-66.

Quinton, Anthony: 1974 Filosofía Política, Fondo de Cultura Económica, México.

Rawls, John: 1971 A Theory of Justice, Oxford University Press, Oxford.

- 1986 Justicia como equidad. Materiales para una teoría de la Justicia, edición de M. Angel Rodilla, Tecnos, Madrid.

- 1989 Justice as Fairness. A Guided Tour, Harvard University, Cambridge (texto fotocopiado, no publicado).

- 1990 Sobre las libertades, Paidós/ICE-UAB, Barcelona. (Orig: The Basic Liberties and their Priority, Tanner Lectures on Human Values, vol. 3, Cambridge University Press, Cambridge (Mass.), 1982).

- 1996 El liberalismo Político, Grijalbo Mondadori, Barcelona. (Orig: Political Liberalism, Columbia University Press, Nueva York, 1993).

Raz, Joseph: 1984 Right-based Moralities, en Waldron 1984, pp. 182-200.

Ross, Alf: 1963: Sobre el Derecho y la Justicia, Eudeba, Buenos Aires, (Orig: On Law and Justice, Stevens \& Sons, Londres, 1958).

- 1971 Lógica de las normas, Tecnos, Madrid, 1971 (Orig: Directives and Norms, Routledge \& Kegan Paul, Londres, 1968).

Ruiz Miguel, Alfonso: 1990 Los derechos humanos como derechos morales, Anuario de Derechos Humanos 6, pp. 149-160.

- 1992 Derechos humanos y comunitarismo. Aproximación a un debate, Doxa 12, pp. 95-114.

Scanlon, T.M.: 1984 Rights, Goals, and Fairness, en Waldron 1984, pp. 137-152. 
Sen, Amartya: 1995 Legal Rights and Moral Rights. Old Questions and New Problems, en Varios 1995 (Tomo II), pp. 203-214.

Singer, Peter: 1984 Ética práctica, Ariel, Barcelona. (Orig: Practical Ethics, Cambridge University Press, Cambridge, 1979).

Smith, Adam: 1987 Investigación sobre la naturaleza y causas de la riqueza de las naciones, Fondo de Cultura Económica, México, (Original de 1776).

Sumner, Lawrence W.: 1990 The Moral Foundationsof Rights, Clarendon Press, Oxford.

Tuck, Richard: 1979 Natural Rights Theories. Their origin and development, Cambridge University Press, Cambridge.

Vernengo, Roberto J.: 1989 Dos ensayos sobre problemas de fundamentación de los derechos humanos, Facultad de Derecho y Ciencias Sociales (UBA), Buenos Aires.

Villey, Michael: 1964 La genèse du Droit Subjectif chez Guillaume d'Occam, Archives de Philosophie du Droit IX, pp. 97-127.

Von Wright, G. Henrik: 1979 Norma y acción. Una investigación lógica, Tecnos, Madrid. (Orig: Norma and Action. A Logical Enquiry, Routledge \& Kegan Paul, Londres, 1963).

Waldron, Jeremy (edit.): 1984 Theories of Rights, Oxford University Press, Oxford.

Walzer, Michael: 1993 Las esferas de la justicia, Fondo de Cultura Económica, México, (Original: Spheres of Justice. A Defense of Pluralism and Equality, Basic Books, 1983).

Wellman, Carl: 1995 Real Rights, Oxford University Press, Oxford.

Varios: 1995 Challenges to Law at the End of the 20 $0^{\text {th }}$ Century, Cooperativa Libraria Universitaria Editrice Bologna, Bolonia. 
$\triangle \quad$ DOXA $23(2000)$ 